ESTUDOS RBEP

\title{
Políticas socioculturais brasileiras e os interesses formativos do Programa Cultura Viva
}

Rodrigo Manoel Dias da Silva

\section{Resumo}

Visa compreender a emergência e a operatividade de políticas formativas de natureza sociocultural cujo objetivo parece situar-se na dinamização de novos ordenamentos sociais, econômicos e políticos, mas, concomitantemente, associados a ações centradas na formação dos atores sociais. Tomou-se o Programa Cultura Viva, do Ministério da Cultura, como experiência analítica privilegiada, a partir de duas estratégias metodológicas: a revisão de seus pressupostos políticos e o acompanhamento desta política em um município brasileiro. Por fim, interpretou-se que estas ações são orientadas por um desejo pedagógico de mobilizar experiências de educação patrimonial, onde a cultura local torna-se conteúdo e prática escolar, ao mesmo tempo que se visibilizou a circulação de pedagogias voltadas à reconstrução de narrativas de sentido social e ao reconhecimento político das produções identitárias locais.

Palavras-chave: políticas culturais; formação cultural; identidade; educação patrimonial. 


\section{Abstract \\ Brazilian sociocultural politics and the formative interests of the Programa Cultura Viva}

The present article aims at to understand the emergency and the operativity of formative politics of cultural nature whose objective seems to place it self enters the dynamic of new social, economic orders and politics, but, concomitantly, associates the action centered in the formation of the social actors. The Programa Cultura Viva, of the Ministry of the Culture, as privileged analytical experience, from two methodological strategies: the revision of its politicial assumptions and the accompaniment of this politics in a Brazilian city. Finally, it was interpreted that these actions are guided by a pedagogical desire to mobilize experiences of heritage education, where the local culture becomes content and practical pertaining to school, at the same time where it was showed circulation of pedagogies come back to the reconstruction of narratives of social direction and to the recognition of the local identities productions.

Keywords: cultural politics; cultural formation; identity; heritage education.

\section{Introdução}

Neste artigo, pretendemos analisar a situação das políticas socioculturais brasileiras, a partir de algumas experiências recentemente implementadas, que articulam interesses na formação dos atores sociais e na reconstrução de narrativas de sentido social (Silva, 2012). De certo modo, estas políticas acompanham uma tendência contemporânea de produzir intervenções culturais, ou político-culturais, nas condições de vida dos habitantes das cidades brasileiras, em alguns casos de sentido estrutural, estas atinentes ou resultantes de direitos e disputas materiais ou valorativas ajustadas a interesses de melhoria nas condições de vida coletiva, ou, em outros, situadas em intervenções educativo-culturais focalizadas na formação cultural dos indivíduos.

A recente percepção do declínio da institucionalidade moderna da escola (Dubet, 2004, 2007) e a ambígua ampliação de suas funções sociais (Cavaliere, 2002) oportunizam a construção de condições de possibilidade para a circulação de múltiplas políticas e narrativas identitárias pelo interior destas instituições de ensino. O ensejo desta situação parece responder ao objetivo de preencher de novos significados ou sentidos o vazio deixado pelo potencial regulatório da modernidade pedagógica. 
Deste modo, inúmeras formas de ação política passam a circular pelo interior das instituições, tal como pelas cidades que as circundam, revelando novas possibilidades de intervenção nos cotidianos escolares, igualmente pela circulação de múltiplas pedagogias que educam os sujeitos para a vida nas cidades. Consoantes a esta perspectiva sociológica, visibilizam-se novas políticas de escolarização que produzem nexos de sentido entre a educação, a cultura, o esporte, o lazer, usados convenientemente para atingir objetivos civilizacionais mais amplos (Yúdice, 2004). A maior parte destas políticas é elaborada tendo por princípios basilares a intersetorialidade, enquanto ação multifocal do Estado, e a interdisciplinaridade, enquanto princípio de racionalização.

No recente período, há uma intensificação das referidas ações que chegam às escolas brasileiras de educação básica, consolidadas por iniciativas intersetoriais e interdisciplinares entre o Ministério da Educação e o Ministério da Cultura, cabendo destacar como exemplares dessa tendência o "Programa Arte, Cultura e Cidadania - Cultura Viva", promovido pela Secretaria de Cidadania Cultural vinculada ao Ministério da Cultura, e o "Programa Mais Educação", promovido pela Secretaria de Educação Continuada, Alfabetização e Diversidade Cultural vinculada ao Ministério da Educação, ou, ainda, o "Programa Segundo Tempo", oriundo do Ministério do Esporte.

Observamos que estas políticas de natureza sociocultural partilham um objetivo, qual seja, a formação cultural dos estudantes. Multiplicam-se, nestes programas, metodologias de trabalho que se alicerçam em oficinas de dança, teatro, musicalidade, expressão gráfica, leitura e produção de textos, cultura e comunicação ou uso de tecnologias na produção e difusão cultural, tanto quanto seus objetivos se comprometem com a construção da cidadania em duas distintas nuanças.

Assim, os interesses formativos mobilizam-se para além das prerrogativas específicas dos setores educativos vinculados à ação estatal, uma vez que operam em situações políticas advindas de diversos flancos do Estado (Dewey, 2008), o que nos parece ser o caso do Programa Cultura Viva. O presente artigo interessa-se em compreender a emergência e a operatividade de políticas formativas de natureza sociocultural cujo objetivo parece situar-se na dinamização de novos ordenamentos sociais, econômicos e políticos, mas, concomitantemente, associados a ações centradas na formação dos atores sociais. Para tal, tomaremos o Programa Cultura Viva como experiência analítica privilegiada.

Para uma exposição mais didática da presente análise, organizaremos a sequência do artigo em três seções textuais. Na primeira, produziremos um diagnóstico sociológico sobre a tendência política contemporânea em investir-se em intervenções socioculturais nas cidades brasileiras, consubstanciada pelo crescente imperativo de uso conveniente da cultura para a solução de problemas sociais (Yúdice, 2004). Em seguida, interessa-nos identificar como estes princípios políticos de intervenção nas cidades engendram políticas socioculturais objetivadas em projetos formativos, onde trataremos de expor alguns princípios e pressupostos do 
Programa Cultura Viva. Na última seção, derivada de pesquisa etnográfica recentemente realizada, exporemos como estas transições políticas e os reordenamentos nas ações culturais são visibilizados em uma situação política em específico; para tal, iremos relatar os modos de construção do projeto de um Ponto de Cultura na cidade de São Luiz do Paraitinga, São Paulo.

\section{Intervenções socioculturais nas cidades brasileiras: um diagnóstico}

Na transição histórica entre os séculos 19 e 20, a principal questão posta aos primeiros especialistas do mundo urbano ante a ascensão do capitalismo era elaborar soluções para recriar ou reconstruir as cidades que haviam sido estruturadas segundo outras modalidades e outras percepções de tempo, espaço e modos de viver, transformando-as em cidades modernas que pulsavam no ritmo imposto pela industrialização, que trazia em si novas exigências à urbanização (Cury, 2002). Havia, portanto, o interesse na adequação das vidas dos indivíduos aos processos de industrialização e urbanização, o que, no caso brasileiro, se deu através de intervenções públicas entre as décadas de 1930 e 1970. No entanto, o advento de transformações sociais associado à necessidade de formulação e implementação de políticas culturais apropriadas à situação definida potencializou novos arranjos à relação entre as políticas culturais e as cidades, sobretudo se considerarmos suas ambivalências, tensões e determinantes.

É nas cidades que observamos o surgimento de políticas e projetos culturais dirigidos para fins específicos (Yúdice, 2004), interessados em produzir, sob matizes diversos, sua imagem singular (Jacques, 2004). ${ }^{1}$ A produção dessa imagem singular efetua-se por alguns processos sociais, operacionalizados desde projetos culturais específicos que conduzem a modos de conceber e habitar a cidade; ou seja, estes projetos tornam-se determinantes aos modos de vida dos indivíduos na cidade.

Os processos urbanos contemporâneos, em especial sob narrativas de globalização (Canclini, 2003), atribuem à cultura um lugar de destaque, tomando-a como estratégia principal de revitalização urbana. De acordo com Jacques (2004), os particularismos culturais de uma cidade geram slogans que podem permitir a marcação de um lugar singular no competitivo mercado internacional, onde turistas e investimentos estrangeiros são objetos de disputa. Tal circunstância produz uma contradição, qual seja: as próprias imagens das cidades, de início derivadas de suas particularidades culturais ou suas excepcionalidades, acabam cada vez mais assemelhadas entre si com a finalidade de tornarem-se competitivas no mercado global. Essa característica pode ser assim descrita:

[...] cada vez mais essas cidades precisam seguir um modelo internacional extremamente homogeneizador, imposto pelos financiadores multinacionais dos grandes projetos de revitalização urbana. Esse modelo visa basicamente o turista internacional - e não
1 Segundo Borja e Castells (1997), é também neste contexto que entra em cena o "City Marketing", o que potencializou a presença ativa das cidades em eventos internacionais, tendo sua consolidação nos anos seguintes. 
o habitante local - e exige certo padrão mundial, um espaço urbano tipo, padronizado. Como já ocorre com os espaços padronizados das cadeias de grandes hotéis internacionais, ou ainda dos aeroportos, das redes de fast-food, dos shopping centers, dos parques temáticos ou condomínios fechados, que também fazem com que as grandes cidades mundiais se pareçam cada vez mais, como se formassem uma única imagem. (Jacques, 2004, p. 24).

Segundo a autora, esta lógica contemporânea é própria inclusive às cidades históricas, localizando-a em "um modelo de gestão patrimonial mundial" pautado por sentidos de homogeneização, porque a preservação de áreas históricas patrimonializadas ocorre através de normas internacionais de intervenção e faz com que todas estas áreas se tornem semelhantes entre si, produzindo efeitos de um processo de museificação urbana, mas em escala global, no qual turistas de todo o mundo se sentem visitando um grande (e único) museu (Jacques, 2004). A memória cultural, cujas discursividades revelam interesse de conservação, no caso brasileiro iniciado com o Programa Cidades Históricas (Calabre, 2009), faz-se secundária quando são construídos cenários urbanos para projetos turísticos.

Esta produção de cenários urbanos é consequência de um processo contemporâneo de espetacularização das cidades (Jacques, 2004), atrelado às estratégias de marketing cultural e marketing urbano, consubstanciado pelas políticas de financiamento cultural voltadas para a construção de novas imagens para as cidades. Assim,

As maiores vedetes são os equipamentos culturais, franquias de museus e suas arquiteturas monumentais - cada vez mais espetaculares e visando a indústria do turismo - que passam a ser as principais âncoras de megaprojetos urbanos. Na nova lógica de consumo cultural urbano, a cultura passou a ser concebida como uma "cultura-econômica", não mais um produto industrializado como no início da indústria cultural, mas sim como uma simples imagem de marca, ou grife de entretenimento, a ser consumida rapidamente. Com relação às cidades, o que ocorre não é muito diferente. A competição é acirrada e as municipalidades se empenham para melhor vender a imagem da marca, ou logotipo, da sua cidade, privilegiando basicamente o marketing e o turismo [...]. (Jacques, 2004, p. 25).

Os interesses pela revitalização de áreas urbanas são engendrados por dispositivos de culturalização do planejamento das intervenções urbanísticas. São projetos para intervenções nos espaços urbanos realizando usos estratégicos dos recursos culturais (Vaz, 2004). A gramática destas intervenções político-culturais na cidade é marcada pelo recorrente uso de novas denominações, desde o início do século 20, geralmente iniciadas pelo prefixo "re": renovação, reestruturação, revitalização, reabilitação, requalificação, regeneração, etc. (Vaz, 2004). Aliás, a "reparação cultural" tem se tornado o modelo privilegiado de planejamento das intervenções na cidade. Tal premissa, muitas vezes, esteve associada à exacerbação de relações entre a ética e a estética, notadamente na visão de artistas e arquitetos (Jeudy, 2006). Ética e 
estética se tornavam precondições para a produção de mecanismos de integração ou acomodação de elementos na urbanidade, tornando cada intervenção um elo entre o passado e o tempo presente, sob alegações celebrativas, monumentalistas ou memorialistas. Hoje, entretanto, conhecemos e experimentamos fenômenos de degradação e destruição, como nos acontecimentos de 11 de setembro de 2001, nos Estados Unidos, que projetam novos desafios às políticas públicas e culturais, pois estas "se veem agora confrontadas com a necessidade de tratar, de um modo ativo, vivo, estético, o que está destinado a desaparecer, o que está aniquilado" (Jeudy, 2006, p. 23). Talvez o primeiro indício deste modelo, observado nas políticas culturais brasileiras, tenham sido as intervenções executadas em áreas centrais e sítios históricos de várias cidades do Nordeste, cujo ícone foi o projeto de recuperação do Pelourinho, em Salvador.

Estas iniciativas eram concebidas e financiadas por administrações municipais e estaduais. No entanto, se considerarmos a boa aceitação de público e os usos político-eleitorais destas iniciativas, identificamos também alguns desses projetos na esfera federal de gestão, os quais trouxeram novas fontes de financiamento para ações de preservação e permitiram a inserção de novos atores nestas lógicas (Sant'anna, 2004). Baseados em fomentos derivados de renúncia fiscal, empréstimo externo ou recursos orçamentários, esses projetos tornam-se locus privilegiado para intervenções culturais na urbanidade; dentre eles, podem ser destacados o Programa Monumenta, gerido pelo Ministério da Cultura, com financiamento do Banco Interamericano de Desenvolvimento, e o Programa de Revitalização de Sítios Históricos, da Caixa Econômica Federal, além do Programa Urbis, do Ministério da Cultura e do Iphan. Outros projetos têm sido desenvolvidos nesta direção, porém trazem alguns desdobramentos que precisam ser analisados. Nas palavras de Cláudia Cury (2002, p. 97):

Esses projetos, que estão sendo implementados em diversas capitais brasileiras, como Recife, Salvador, Rio de Janeiro, João Pessoa e São Paulo, certamente nos agrada sob o ponto de vista da recuperação arquitetônica e do valor cultural que apresentam, bem como a possibilidade das áreas de lazer e convivência que estes centros antigos têm possibilitado. As memórias e identidades destas áreas centrais das cidades brasileiras foram transformadas ao longo dos séculos, perdendo qualquer identidade com outros tempos históricos.

As intervenções públicas realizadas na cidade de São Paulo entre 1995 e 2001 permitem a visualização ilustrativa de uns destes traços, mesmo que não possam ser generalizados. Embora já existissem ações de revitalização do Centro desde os anos de 1930, foi na segunda metade da década de 1990 que novas diretrizes estratégicas na gestão das áreas centrais passaram a ser implementadas, época em que vigorava a reformulação de políticas federais para a cultura. Deste modo, algumas intervenções culturais entraram na agenda das políticas públicas "para a requalificação física e simbólica do Centro de São Paulo" (Kara-José, 2007, p. 177), principalmente as políticas estaduais. 
O interesse empresarial pelo marketing cultural contribuiu para o uso da cultura como viés destas implementações, desencadeando o aumento de recursos públicos a elas destinados. A atuação mais evidente no centro de São Paulo foi a mobilizada pela Secretaria Estadual da Cultura, onde o uso atribuído à cultura ao longo desta gestão ficou declarado na fala do secretário Marcos Mendonça, o qual mencionara: "trabalhamos para usar a cultura como instrumento para a revitalização do centro de São Paulo e como instrumento de transformação social" (Kara-José, 2007, p. 178). As leis de incentivo fizeram-se necessárias e complementares aos projetos culturais de intervenção urbana, cujo mapeamento reconheceria os distritos da Sé e República, seguidos pelos bairros da Luz e Campos Elíseos. Em todas essas regiões ocorreram projetos de requalificação urbana, porém foi na região da Luz que os interesses projetados estavam voltados para a criação de um polo cultural.

A política cultural implantada por Mendonça na Secretaria Estadual da Cultura teve por consequência a multiplicação de projetos culturais na região da Luz, os quais aliavam recuperação urbana e restauração de patrimônio arquitetônico, fundamentados, por um lado, no conjunto monumental de excepcionalidade cultural e, por outro, por tratar-se de uma região da cidade constituída por contradições socioespaciais. A ênfase destes múltiplos projetos, além de atrair turismo, estava na criação de equipamentos culturais de maior porte como condição para captação de recursos e investimentos privados dirigidos à transformação da área.

As áreas urbanas da Lapa, no Rio de Janeiro, também passaram por processos de revitalização de conteúdo semelhante. Nessa experiência, as políticas culturais incentivaram, promoveram e realizaram diversas atividades localizadas na cidade, de variado alcance, duração e agrado ao público (Vaz, 2004; Vaz, Jacques, 2006). O projeto de intervenção cultural na Lapa teve natureza pública, a cargo da Secretaria de Cultura do Estado do Rio de Janeiro, com manifesto objetivo de implementar atividades culturais em edificações antigas selecionadas para restauração de suas estruturas físicas em ambientes urbanos considerados relevantes no contexto histórico da cidade (Silveira, 2006). Associado às iniciativas públicas, ações da iniciativa privada possibilitaram a restauração de diversos sobrados e sua utilização para diversos fins comerciais, culturais, de lazer e mesmo social. As dinâmicas desenvolvidas preconizavam a implantação de atividades culturais para uso da coletividade, relacionadas em parte com a identidade do lugar (Silveira, 2006), o que, de certo modo, não expressou o território cultural rico e contraditório ali presente, marcado por inúmeros tensionamentos. Carmen Beatriz Silveira (2006, p. 102-103) assim descreve essa situação:

Verificamos, nesse espaço que congrega distintos grupos de uma sociedade de profundos contrastes sociais, uma possibilidade de convivência num lugar com relativa, mas importante diversidade social. Um lugar onde os focos de resistência poderiam restringir processos de espetacularização e gentrificação, por que se instalam num "ambiente cultural" que tem uma força de criação artística e de desenvolvimento 
urbano local, tornando-se também atraente para grupos de investidores culturais voltados para ações sociais transformadoras.

As experiências narradas acima evidenciam traços significados das políticas socioculturais contemporâneas nas interfaces entre os projetos culturais e a cidade, o que permite constatarmos a dinamicidade das relações em jogo e os múltiplos usos da cultura nestes contextos. Como observa Martinell (2003), "a cidade é o espaço público onde se dá a cultura ao vivo".

Estes traços trouxeram, a nosso ver, duas consequências analíticas, que, nos termos de Schutz (1974), são desdobramentos dos "novos fundamentos de praticabilidade" às referidas políticas no tempo em que vivemos:

1. Estes projetos culturais brasileiros de intervenção nos espaços urbanos iniciados no final do século 20, em muitos casos, desencadearam estratégias de planejamento e gestão das cidades que nem sempre demonstraram preocupação que não fosse o mercado. As intervenções culturais na Lapa, no Rio de Janeiro, e no bairro da Luz, em São Paulo, do mesmo modo que revelaram tendências destas políticas urbano-culturais, revelaram igualmente suas consequências para as populações locais. No entanto, outra situação carioca ilustra estas circunstâncias: o processo de mudança urbana realizado na Praça Tiradentes. O projeto de revitalização da Praça Tiradentes, em oito anos de implementação, efetivou pouco de suas pretensões de revitalização do lugar, marcado por um conjunto de desconexões entre as ações do poder público e os problemas a priorizar, como descreve Silveira (2006, p. 97):

Em diversos momentos verificamos que, ao impor a implementação do projeto de Revitalização da Praça Tiradentes, o poder público ignorou as práticas espaciais existentes na praça e seu entorno. Ao observarmos o interesse primordial na restauração de alguns prédios eleitos como espaços simbólicos para a cidade, constatamos que o Projeto Social não logrou resultados substantivos.

Nas etapas iniciais do projeto de intervenção, a questão social estava sendo tratada como indesejável, tratando-se de obstáculos aos objetivos da restauração física e da alteração dos usos das edificações recuperadas. Órgãos municipais de assistência social foram chamados a negociar com as prostitutas que trabalhavam no entorno da praça, chegando a proporlhes mudança de profissão, através de cursos de artesanato e alternativas profissionais. Assim, as entidades envolvidas mobilizadas não atentavam para as realidades dinâmicas em jogo. Afirma Silveira (2006, p. 98):

Observamos aqui a recorrência da higienização e da limpeza urbana, exprimindo um imperativo dessas propostas. O projeto tinha como um dos seus pressupostos transformar a opção de vida e de trabalho das prostitutas locais, que, no entanto, revelaram-se atentas aos chamados projetos de "revitalização", potenciais projetos de expulsão dos usuários indesejados. No caso da Praça Tiradentes, houve uma reversão da ideia inicial do poder público, e as prostitutas passaram a participar ou a se mobilizar para participar de eventos, quando não eram convidadas. 
A literatura crítica destas relações entre políticas culturais e territórios urbanos nos mostra que os resultados destas intervenções contemporâneas, em muitos casos, revelam apenas espaços comerciais enobrecidos pelo consumo cultural (Vaz, 2004; Vaz, Jacques, 2006). Quanto a esta observação, Otília Arantes reitera que o consumo cultural, quando alcança um refinamento artístico ostensivo, torna-se garantia para o clima de negócios (Arantes, 2009, p. 29), no cenário em que as populações locais passam por processos de gentrificação, onde a cultura, através de uma "estratégia fatal" (Arantes, 2009), passa a ser o principal negócio das cidades. Além da repulsão das populações, outra consequência das aproximações entre políticas culturais e negócios urbanos é a especulação imobiliária (Kara-José, 2007).

2. As políticas culturais contemporâneas, por outro lado, associando-se a um conjunto de ações que recuperam as identidades e reconstroem narrativas de sentido social (Silva, 2012), também podem ser interpretadas ao oportunizarem proposições sociais e, mesmo, a geração de empregos e renda, contribuindo na contenção das dinâmicas desiguais da sociedade brasileira, como se destacam, por exemplo, as ações de "museificação" (Anico, 2005; Corrêa, 2007). Outras maneiras já analisadas na bibliografia apontam para a formulação de projetos envolvendo o artesanato (Rotman, 2007), o turismo (Farias, 2001) e suas possibilidades de modernização turística, assim como a proposição de eventos (Xavier, 2007).

Quando a cultura assume estas novas prerrogativas nas discursividades políticas e nas práticas sociais, em distintos âmbitos, repercute de maneira significativa no contexto nacional. Em nosso país, isso ficou explícito no Plano Nacional de Cultura. As diretrizes políticas da Unesco no Brasil, por sua vez, acompanharam esta tendência, ao apontar que "o Brasil é campo fértil para o desenvolvimento de projetos em que a cultura tenha papel central, devido a sua notável diversidade criativa" (Unesco, 2006, p. 43).

Nas diretrizes gerais do Plano Nacional de Cultura, encontramos, além de outras dimensões, os sentidos de valor econômico vinculados às práticas culturais brasileiras, tal como já assinalara Farias (2001). Nos termos do documento produzido pelo Ministério da Cultura:

Nesse contexto, reconhece-se hoje a existência de uma economia da cultura que, bem regulada e incentivada, pode ser vista como um vetor de desenvolvimento essencial para a inclusão social através da geração de ocupação e renda. (Brasil. MinC, PNC, 2008, p. 30).

Em todo caso, cumpre reiterarmos que as relações entre cidades e as culturas se redefinem, na contemporaneidade, intensificando um conjunto de dinâmicas societais catalisadoras de projetos culturais de intervenção urbana, além de um conjunto de outras iniciativas públicas.

Cabe, ainda, interrogarmos sobre outros interesses em jogo nestas posições políticas. Embora descontínuas (Rubim, 2011), estas intervenções não visaram exclusivamente às dimensões materiais das culturas presentes nas cidades brasileiras, muitas vezes voltadas a seus potenciais econômicos. Em alguma medida, torna-se possível visualizarmos que 
estes princípios políticos de intervenção nas cidades engendraram políticas socioculturais objetivadas em projetos de formação de atores sociais, sobretudo quando as políticas culturais brasileiras recuperaram a pertinência social quando da presença de Gilberto Gil no Ministério da Cultura. A transição de um modelo político de estreitamento das questões culturais, caso das gestões presidenciais de Fernando Henrique Cardoso, para uma retomada dos objetivos socioculturais para o setor, ainda que insuficientes, nos períodos administrativos de Lula, é o cenário da argumentação da seção textual a seguir.

\section{O Programa Cultura Viva e os interesses formativos}

Em 2003, Luiz Inácio Lula da Silva assume a presidência da República, e, em seu auxílio, Gilberto Gil assume o Ministério da Cultura. O setor foi reformulado, e foram criadas novas secretarias: de Políticas Culturais, de Fomento e Incentivo à Cultura, de Programa e Projetos Culturais, do Audiovisual e de Identidade e Diversidade Cultural, com ênfase na produção de uma postura ativa do Estado no segmento. Associada ao manifesto e efetivo interesse ministerial em democratização cultural, uma nova lógica de distribuição de recursos e implementação de políticas passava então a ser efetuada:

Ao longo da primeira gestão do ministro Gil, algumas medidas foram tomadas para buscar diminuir o processo de concentração regional e setorial. Uma delas foi investir no processo de seleção de projetos por meio de editais, tanto internos, quanto por intermédio dos maiores investidores na lei, como é o caso da Petrobrás. (Calabre, 2009, p. 122).

As mais consistentes críticas da equipe ministerial aos governos anteriores referiam-se aos mecanismos de financiamento através das leis de incentivo. Segundo estes, "os incentivos fiscais não direcionariam recursos segundo prioridades políticas, deixando às empresas a decisão sobre a alocação final dos recursos públicos" (Barbosa, 2008, p. 78), o que fragilizava a ação do Estado. Outra limitação observada dizia respeito a sua reduzida abrangência territorial, sobretudo se considerarmos a concentração dos recursos na Região Sudeste do Brasil (Barbosa, 2008).

Estava na agenda do Ministério uma reestruturação mais ampla das políticas culturais, baseada, fundamentalmente, em dois procedimentos: a formulação de um Plano Nacional de Cultura e a produção de um Sistema Nacional de Cultura. Desde o início de 2005, as ações ministeriais estavam voltadas para um Plano Nacional; mediante este interesse, foi realizada a $1^{\text {a }}$ Conferência Nacional de Cultura, cujas reuniões preliminares seriam municipais, estaduais e interestaduais, com a finalidade de colher subsídios para o plano (Calabre, 2009). Consoante ao processo, encontrava-se o Sistema Nacional de Cultura, com o objetivo de voltar-se para ações integradas no setor, evitando distorções e sobreposições de iniciativas e legislações, o que vinha ocorrendo com as leis de patrimônio histórico e cultural, por exemplo. 
Não obstante inúmeras ações dirigidas para a cultura no período administrativo do presidente Lula, uma delas, a nosso ver, tornou-se exemplo das novas estratégias postas em operação pelo Ministério da Cultura: o Programa Cultura Viva. Criado pelas Portarias Ministeriais $n^{\circ}$ 156/2004 e no 82/2005, o programa visava a articulação de cinco ações: Pontos de Cultura, Agentes Cultura Viva, Cultura Digital, Escola Viva e Griôs-Mestres dos Saberes, com o objetivo de promover o acesso à fruição, produção e difusão cultural, através de mecanismos de cooperação social. As seleções de projetos davam-se através de editais, como a citação abaixo ilustra:

As seleções seriam feitas por meio de editais públicos, e cada projeto de Ponto de Cultura selecionado receberia recursos da ordem de R 150 mil ao longo de cinco semestres e também passaria a ser beneficiado por ações e parcerias formalizadas pelo MinC, visando à ampliação das atividades realizadas. (Calabre, 2009, p. 124).

Embora o financiamento das políticas governamentais ainda estivesse dependente das leis de incentivo (Rubim, 2011) e seguramente insuficiente (Barbosa, 2008), estas ações realizaram uma aproximação e um diálogo com setores da sociedade que antes não estavam presentes na agenda de discussões públicas, além de contemplar financiamento e interesse político a agentes culturais que não receberiam, em circunstâncias anteriores, como mestres da cultura popular, interiorizando geograficamente estas políticas, como explicita Silva (2011). Embora o quadro de redução orçamentária não tenha sido alterado com consistência, o Programa Cultura Viva ampliou as possibilidades de obtenção de recursos e permitiu que inúmeros projetos recebessem fomento estatal, constituindo um campo concorrencial mais ampliado. Em nossa análise, este campo concorrencial, observado nos projetos de Pontos de Cultura, reforça a tendência à responsabilização individual por seus projetos e pela obtenção de financiamento público ou privado para sua implementação. Mesmo com a nova atitude ministerial, a escassez de financiamento, associada aos dispositivos concorrenciais através de editais, conforma e acentua estes campos de disputa por recursos.

Além disso, o Programa Cultura Viva incorporou uma segunda mudança fundamental no período administrativo de Lula: a pluralização da questão identitária (Barbalho, 2007). A própria identidade nacional, tema prioritário das políticas culturais desde a Era Vargas, torna-se pluralizada, como diagnostica Alexandre Barbalho (2007, p. 52):

A diversidade não se torna uma síntese, como no recurso à mestiçagem durante a era Vargas e na lógica integradora dos governos militares, nem se reduz à diversidade de ofertas em um mercado globalizado. A preocupação da gestão Gilberto Gil está em revelar os brasis, trabalhar com as múltiplas manifestações culturais, em suas variadas matrizes étnicas, religiosas, de gênero, regionais, etc.

Essa percepção revela-nos o interesse do Estado em contemplar, em seus campos de intervenções, atores e grupos antes não reconhecidos 
pelas ações ministeriais, caso é o caso das culturas populares. Na visão de Célio Turino, então coordenador do programa, essa visão implicaria um Estado ampliado, promotor de acesso aos meios de formação, criação e fruição de experiências culturais, mediante vínculos de parceria com agentes culturais, artistas, professores e militantes sociais, atento às mudanças culturais de nosso tempo. Mas, objetivamente, qual o público prioritário do Programa Cultura Viva?

- Populações de baixa renda, habitantes de áreas com precária oferta de serviços públicos, tanto nos grandes centros urbanos como nos pequenos municípios;

- Adolescentes e jovens adultos em situação de vulnerabilidade social;

- Estudantes da rede básica de ensino público;

- Professores e coordenadores pedagógicos da educação básica;

- Habitantes de regiões e municípios com grande relevância para a preservação do patrimônio histórico, cultural e ambiental brasileiro;

- Comunidades indígenas, rurais e remanescentes de quilombos;

- Agentes culturais, artistas e produtores, pesquisadores, acadêmicos e militantes sociais que desenvolvem ações de combate à exclusão social e cultural. (Brasil. MinC, Programa... [2013]).

A informação do público-alvo do programa permite-nos analisar uma terceira mudança importante, esta no foco das políticas de natureza sociocultural, qual seja, a mútua implicação ou recíproca determinação entre as políticas educacionais e as de ação cultural. O Programa Cultura Viva toma as escolas públicas como locus privilegiado para suas mais diversas iniciativas e prevê iniciativas pedagógicas para seus docentes e discentes. Ao mesmo tempo, expõe interesse em muitas expressões formativas voltadas às diversificadas manifestações sociais e culturais brasileiras, ora com interesse em conservação patrimonial, ora em aprendizados da cultura local em estratégias de educação patrimonial ou mesmo em uso destas manifestações como conteúdo para projetos sociais (Yúdice, 2004).

Então, se observamos uma fragilização dos dispositivos ordenadores das instituições de ensino (Dubet, 2004; 2007), as políticas socioculturais de nosso tempo são desafiadas pela irradiação de múltiplos agenciamentos culturais (Silva, 2012), uma vez que, paradoxalmente, por um lado, constroem um campo concorrencial entre projetos e atores culturais em busca de diversos recursos (Yúdice, 2004) e, por outro, permitem a reconfiguração de modelos valorativos voltados para a reconstrução dos sentidos sociais (Dewey, 1970). Neste sentido, implica pensarmos que a racionalização dos agenciamentos culturais, através de editais de concorrência como técnica de vida contemporânea, consolida um campo identificável de experiências competitivas entre atores, mas contribui na formação de um modelo valorativo de democratização destas políticas, uma vez que atua na promoção de uma disputa mais justa e criteriosa por recursos públicos, o que pretende evitar o clientelismo e o patrimonialismo típico das relações entre os atores e o Estado. 
Na próxima seção, pretendemos expor a implementação do programa em uma cidade brasileira, a partir de pesquisa etnográfica que desenvolvemos no lugar entre 2010 e 2011 associada a entrevistas semiestruturadas realizadas com seus agentes públicos. Os dados analisados, em sua maioria, referem-se à situação pedagógica de planejamento das ações culturais de um Ponto de Cultura em São Luiz do Paraitinga, São Paulo, onde nosso interesse consistirá em identificar suas tensões, objetivos e interesses em jogo nesse plano.

\section{As intervenções culturais na reconstrução de São Luiz do Paraitinga, SP}

São Luiz do Paraitinga é um município localizado no interior do Estado de São Paulo, no Vale do Paraíba Paulista, distante 170 quilômetros da capital do Estado, situado no alto da Serra do Mar e tendo como municípios limítrofes Taubaté (ao Norte), Ubatuba (ao Sul), Lagoinha (a Leste) e Redenção da Serra e Natividade da Serra (a Oeste). Sua área é de 617 km², atravessada por vários cursos de água: Rio Paraitinga, Rio Paraibuna, Rio Paraíba, Rio Claro, Ribeirão Prata, Ribeirão Turvo e Ribeirão Chapéu. Do ponto de vista histórico, uma pequena povoação começou a constituir-se no lugar em meados de 1769, vindo a constituir-se em vila no ano de 1773, quando seu padroeiro passou a ser São Luís, bispo de Tolosa. No ano de 1857 elevou-se a cidade e, em 1873, à denominação "Imperial Cidade de São Luiz do Paraitinga". Data deste período um conjunto de edificações que urbanizaram a pequena cidade, que chegou a ter quinze mil habitantes nos anos de 1930, quando a produção da rapadura e outros derivados de cana tiveram seu apogeu nos circuitos econômicos regionais. No século 19, sua economia assentava-se no setor cafeeiro, o qual promoveu o desenvolvimento de toda a região, e isto desencadeou a produção de uma variedade de gêneros agrícolas, tornando-se lugar de abastecimento das tropas que transportavam café do Vale do Paraíba para o litoral paulista. O entorno da cidade é marcado por belas paisagens naturais, especialmente a floresta remanescente da Mata Atlântica, hoje protegida pela Floresta Nacional da Serra do Mar, criada em 1977 (Lopes, Silva, Silva, 2011).

O desenvolvimento urbano acompanhou um conjunto de transformações sociais, políticas e econômicas dadas em âmbitos regionais; é o caso da inauguração, em 1927, da rodovia Rio de JaneiroSão Paulo, a qual passava pela nucleação urbana de Taubaté, uma das principais cidades do Vale do Paraíba, ou, ainda, o do declínio da produção cafeeira na região e a crescente potencialização da indústria como principal estratégia econômica (Lopes, 2006). No entanto, a localização geográfica de São Luiz do Paraitinga a tornou relativamente isolada dos fluxos de modernização desenvolvidos às margens da Rodovia Presidente Dutra, o que permitiu a manutenção de certos traços tradicionais de formação da cultura caipira (Lopes, Silva, Silva, 2011). 
Além do desenvolvimento urbano-industrial observado em todo o País entre as décadas de 1930 e 1970, destacam-se ainda outros ciclos de desenvolvimento econômico vividos no município, que podem ser associados a festividades religiosas e culturais. Como observa Lopes (2006, p. 202):

Cidades como São Luiz do Paraitinga, vivendo ciclos determinados pela produção agrícola, desenvolveram um calendário rico de festas religiosas que culminavam na realização de um grande evento anual, como a festa do Divino, na própria São Luiz. Outras cidades da região desenvolveram um calendário fragmentado ou vinculado a um padrão de relações mais especificamente direcionado, como Aparecida, com sua Festa de São Benedito, que reunia congadas e moçambiques pelas ruas da cidade.

Muitas de suas edificações históricas foram patrimonializadas através de processo de tombamento, em 1982, pelo Conselho de Defesa do Patrimônio Histórico, Arqueológico, Artístico e Turístico (Condephaat), entidade vinculada à Secretaria Estadual da Cultura. A partir de então, São Luiz do Paraitinga passou a ser a cidade paulista com o maior número de imóveis tombados como patrimônio histórico e cultural, tendo mais de 400 imóveis. Porém, o caso deste município difere de outros que também possuem imóveis em semelhantes situações, o fato de a maioria destes serem ainda utilizados como residência. Esse patrimônio arquitetônico tombado, associado a práticas culturais, festivas ou religiosas, fez de São Luiz interessante lugar de visitações turísticas. Então, desde 2002, a cidade se tornou uma das estâncias turísticas do Estado de São Paulo (aprovado pela Lei Estadual no 11.197, de 5 de julho de 2002).

Em entrevista, Eduardo de Oliveira Coelho, responsável pelo Departamento de Turismo no município, mencionou as potencialidades culturais de São Luiz, que, conhecidas regionalmente, se tornam evidentes:

Nós temos a cultura tradicional caipira aqui em São Luiz do Paraitinga, um dos últimos redutos de caipiras do Estado de São Paulo. Temos o maior conjunto arquitetônico do Estado também, de casas tombadas pelo Condephaat e, recentemente, pelo Iphan, totalizando 433 casas tombadas. Aqui nós temos a questão da musicalidade, que é muito forte, terra de Elpídio dos Santos - grande músico aqui, influenciou muitas gerações, fazia as trilhas sonoras dos filmes do Mazzaropi na década de 40, e até hoje tem música dele sendo tocada aqui. Inclusive as marchinhas de carnaval, que é de forma inédita que acontece aqui em São Luiz. (Eduardo, 38 anos, secretário municipal).

Como observou João Rafael dos Santos (2008), embora indicadores apontem para a existência de êxodo e empobrecimento da população, tornar-se estância turística estadual ampliou com intensidade a arrecadação municipal, pois do valor de R\$ 6.314.100,00 em 2001, ampliou-se para R\$ 15.757.400,00 em 2007 (Santos, 2008). A ampliação deste índice de arrecadação expressa a relevância do turismo na economia municipal, visto na presença de pousadas, hotéis, restaurantes e lojas de artesanato. Tornar-se estância turística trouxe ainda desafios aos modos de organização das políticas culturais na cidade. 
A política de cultura em São Luiz, tradicionalmente, foi pautada por três traços fundamentais: a patrimonialização, através de processos de tombamento (caso do Condephaat, em 1982, e do Iphan, em 2010); a conformação de calendários regionais festivo-religiosos (Festa do Divino Espírito Santo, por exemplo); o tangenciamento das ações sociais às condições instituídas, como a Prefeitura e a Igreja Católica, como sinaliza Santos (2008). A priori, os traços acima apontados permitem uma interpretação destas políticas como incrementalistas, porém as condições turísticas recentes trouxeram novas situações à cidade: novos eventos foram promovidos e outros atores passaram a agenciar projetos, entre estes os eventos contemporâneos de Carnaval, a Sociedade de Observadores de Sacis (Santos, 2008) e o Festival da Música Brasileira. Estas ações, além de uma ênfase nos objetivos econômicos próprios de atrativos turísticos, posicionaram elementos tradicionais da cultura luizense, redimensionando os interesses em jogo diante da atualização midiática observada, por exemplo, a repercussão na mídia regional dos recentes festivais de marchinhas e do próprio carnaval da cidade.

No entanto, algumas modificações significativas em São Luiz ainda estavam por acontecer, por fatores inesperados: no primeiro dia do ano de 2010, parte da cidade foi destruída por uma enchente, e, quando o Rio Paraitinga transbordou, grande contingente da população urbana e rural foi atingida, com perdas e avarias em suas residências e bens móveis, entre muitas outras perdas sentimentais e simbólicas. O fato é veiculado pela imprensa brasileira em todos os dias da primeira semana do ano e causa comoção geral. Muitos prédios de valor histórico foram destruídos (18 foram destruídos e 65 tiveram algum tipo de avaria). Iniciam movimentos de solidariedade em favor da cidade por toda a região, uma vez que foram instalados postos de recolhimento de doações em Taubaté, São José dos Campos e São Paulo, além de campanhas pela mídia solicitando quaisquer doações.

Desde as semanas subsequentes ao alagamento, além das campanhas para arrecadação de dinheiro, colchões, cobertores, materiais de higiene e limpeza, água e alimentos não perecíveis, observaram-se inúmeros eventos culturais que foram sendo divulgados e promovidos pelo site do município e em outros espaços da imprensa regional e nacional. Os iniciais processos de reconstrução da cidade e das vidas das pessoas dependiam de recursos, e inúmeras iniciativas foram mobilizadas: promoção e realização de partidas de futebol com jogadores ou ex-jogadores de futebol profissional, cujos lucros dos ingressos seriam remetidos às "vítimas da enchente", como era definido; cervejarias, bares e boates da cidade de São Paulo e do Vale do Paraíba promoviam shows beneficentes, ao mesmo tempo que espetáculos teatrais eram produzidos e encenados com a mesma finalidade, além de espetáculos de dança e canto; e instrumentistas de diversos estilos trabalharam em arrecadações em prol do município, fossem artistas sem vínculo com a cidade ou outros que já circulavam por São Luiz do Paraitinga, normalmente bastante frequentada por muitos músicos e artistas. 
Um caso específico destas dinâmicas de reconstrução da cidade de São Luiz do Paraitinga parece-nos sinalizar a conformação de um modelo de agenciamento de recursos às políticas culturais contemporâneas, que passaremos a delinear na sequência do texto.

Como sabemos, a gestão Gilberto Gil no Ministério da Cultura potencializou novos projetos e propósitos para as políticas de cultura nacionais, muito embora suas lógicas fundamentais não trouxessem ruptura substancial com a gestão que lhe antecedeu. Uma destas novas políticas foi o Programa Cultura Viva.

Como observamos na seção anterior, o Programa Cultura Viva incorporou uma mudança importante no período administrativo de Lula: a pluralização da questão identitária (Barbalho, 2007). Daí decorre sua principal ênfase:

O Programa Arte Cultura e Cidadania - Cultura Viva contribui para o enfrentamento de problemas relativos às carências de instrumentos e estímulos para a produção e circulação da expressão cultural local, e também pode contornar o problema do isolamento das comunidades em relação às novas tecnologias e aos instrumentos de produção e educação artístico-culturais disponíveis em outros meios. (Silva, Araújo, 2010, p. 38).

Essa dimensão do programa parece ter sido usada convenientemente (Yúdice, 2004) no auxílio do município de São Luiz do Paraitinga após a enchente. Segundo nossos informantes na cidade, no edital de 2009, no qual projetos do município foram submetidos, nenhum havia ficado entre os selecionados para Pontões de Cultura (pontos especiais encarregados de estabelecer articulações entre diversos outros) nem entre Pontos de Cultura (em edital estadual). Porém, dias depois da enchente, quando se normalizou o acesso ao lugar, a presença de Célio Turino, então coordenador do programa em São Luiz, consubstanciada ao processo de tombamento das edificações de seu núcleo urbano pelo Iphan, produziu expectativas em torno da seleção de pontos de cultura e ações emergenciais dirigidos à contribuição nas dinâmicas de reconstrução urbana, o que veio, na sequência, a ocorrer. O próprio Ministério notificou em seu site, um mês após o incidente, suas iniciativas na reconstrução da cidade:

Arrasada pelas chuvas do começo do ano - a cidade sofreu inundação e teve grande parte de suas construções históricas destruídas -, São Luiz do Paraitinga vê ameaçado o turismo que garante suas receitas. Os artistas e artesãos luizenses, que já perderam grande parte de seu acervo com a enchente, também se veem ameaçados pelo cancelamento das atividades culturais no município. Diante disso, diversas pessoas e organizações ligadas à cidade estão promovendo ações de apoio às suas atividades culturais. O Ministério da Cultura, reconhecendo a importância da garantia do patrimônio imaterial de São Luiz do Paraitinga, do resgate da autoestima do povo luizense, e da economia da cultura que move a cidade, apoia tais ações e realiza uma série de projetos junto aos artistas, artesãos e produtores culturais. (Brasil. MinC, São Luiz..., 2010). 
Essa situação promoveu um campo de agenciamentos de recursos aos atores voltados à produção de projetos qualificados e à consolidação de parcerias para sua efetuação, num cenário marcado por processos concorrenciais individualizados, embora a prerrogativa da seleção fosse institucional. Porém, além das concorrências, estas disputas revelam-nos outra característica de um modelo específico de agenciamento, qual seja, o interesse na formação cultural. Para ilustrar tal tendência, relataremos a experiência de planejamento/construção de um projeto de Ponto de Cultura no município: o Pontão Cultura Caipira.

\section{Pontão Cultura Caipira}

Pedro, 45 anos, comerciante natural de Catuçaba, distrito de São Luiz do Paraitinga, exerceu, além de sua experiência profissional, atividades na política municipal, tendo sido coordenador de cultura e, também, por dez anos, coordenador de esporte. Relatou, em entrevista exposta a seguir, suas inserções na vida cultural luizense, em música, grupos folclóricos, banda fanfarra, composições artísticas e nos festejos carnavalescos. Sua atuação no Pontão Cultura Caipira explicita objetivos formativos que pautam seus agenciamentos culturais.

Segundo nosso interlocutor, no ano de 2009, na Festa do Divino Espírito Santo, o município recebeu a visita de Célio Turino, então atuando no Ministério da Cultura, o qual apresentou aspectos sobre a importância do Programa Cultura Viva para o Brasil e para São Luiz do Paraitinga, explicando o funcionamento do sistema. Ficou dois dias na cidade, quando se reuniu com toda a população, chamou os interessados e falou da possibilidade de São Luiz obter um Ponto de Cultura. Na ocasião, enalteceu o município - que, entre as cidades paulistas, detinha um experimento cultural criativo -, ao citar e caracterizar o carnaval, as marchinhas, a identidade musical de São Luiz, a Festa do Divino e, principalmente, ao referir-se à ausência histórica de apoio do governo estadual ou do federal. Disse ainda que a cidade possuía condições de manter um Ponto de Cultura, ou mais de um, e havia interesse governamental neste tipo de ação.

Após o entendimento de que se tratava de um edital, de uma concorrência pública, Pedro e sua esposa, formada pela Unesp e com experiência em ação social, decidiram chamar os interessados para uma reunião e realizaram o Primeiro Congresso de Cultura de São Luiz do Paraitinga. O interesse fundamental era reunir pessoas para discussão, formulação e redação de um projeto, além de selecionar uma entidade proponente necessária a sua submissão. A discussão coletiva caminhava no sentido de obter um Pontão de Cultura, com recursos do Ministério da Cultura, visando o máximo do valor financeiro, cerca de um milhão de reais, outro projeto voltado a assumir um Ponto de Cultura, de cerca de 500 mil reais, e, ainda, a pretensão de pleitear um Ponto Estadual, no valor de 180 mil reais. No entanto, essa situação desencadeou um campo 
conflitivo de disputas por propostas e recursos. Em meio às disputas, nosso informante optou pela proposição individual, vejamos:

Todo mundo junto, ficou complicado. Chegou no meio do caminho, um saiu para lá, outro para cá e ocorreu o seguinte: eu tinha já um projeto. Quando eu trabalhava na prefeitura, durante dois anos eu fiquei ali no museu, me colocaram ali para gerenciar a cultura e, como local de trabalho, era o Museu Oswaldo Cruz, o Museu Histórico e Pedagógico Oswaldo Cruz, sob a direção do Departamento de Museus e Arquivos da Secretaria da Cultura. Lá nunca teve um acervo do Oswaldo Cruz direito, vinham e voltavam objetos, montaram com alguns móveis antigos que vieram de doações, mas um acervo mesmo não tinha. Então aquela casa enorme, aquele jardim lindo, e eu criei um projeto lá, por coincidência eu coloquei o nome do projeto lá de Cultura Viva, que é o nome do projeto do governo federal. Quando cada um foi para um canto, pensei em mandar o projeto, mas todos os outros foram concorrer no edital estadual. Eu não quis concorrer no edital estadual, porque o projeto que eu tinha era grande para poucos recursos, então tentei no edital do governo federal. (Pedro, 45 anos).

Ao reconhecer que se forjava um campo conflitivo mais intenso em torno do edital estadual, Pedro decidiu ampliar suas projeções, desde experiências prévias (Schutz, 1974), e formular um projeto mais amplo para concorrer ao edital federal. Ele ainda esclareceu como se deu a redefinição e busca por entidades e indivíduos que apoiassem o projeto:

Remanejei o projeto que era para a Casa Oswaldo Cruz e conversei com o padre, na época, isso era em junho, e tem um centro de pastoral que está sendo usado hoje como igreja provisória. Fui lá, conversei com o padre, mostrei o projeto a ele, e ele concordou em ser um parceiro. A gente ia executar o projeto nas dependências do centro pastoral. Encaminhamos o projeto e a proponente nossa foi a Casa da Amizade, das mulheres dos rotarianos. Aí, de 1.200 projetos, o meu ficou entre os 800 , depois entre os 200 , foi ficando e aí quando ficou entre os 80 , não foi selecionado. Foram contemplados 40 projetos, e o meu ficou para trás. (Pedro, 45 anos).

A notícia da desclassificação do projeto entristecera seus proponentes. No entanto, ainda guardavam esperanças de ampliação do programa no Estado de São Paulo, e, nesta situação ideal, seu projeto poderia ser contemplado. Realizou contatos telefônicos com o Ministério, e aguardava para abril a possibilidade de recebimento de novos recursos. Mas, com o evento da enchente, algumas mudanças nos cursos de ação ocorreriam, e Célio Turino voltaria à cidade antes do esperado. Pedro narra este episódio:

No dia que baixou o rio, o Célio Turino esteve aqui. Esteve aqui olhando o restaurante, conversamos, ele viu as coisas como estavam, tudo virado de ponta cabeça. Falou que o ministério estaria apoiando São Luiz do Paraitinga, que não iria desamparar a cidade, disse que era para nós ficarmos calmos que as coisas voltariam aos seus lugares. Aí surgiu a história do Ponto de Cultura na conversa e ele me falou que o meu estaria dentro do esquema. Acho que foi meio em caráter especial ou emergencial, ele veio em caráter especial, eu recebi a informação de Brasília e tive que remodelar de novo o projeto para a realidade que já 
tinha ocorrido, direcionar o projeto para as pessoas que perderam os seus pertences, digamos assim as pessoas mais excluídas, que realmente trabalham com cultura e estavam passando por este aperto. Então, o projeto está nesse sentido. (Pedro, 45 anos).

O advento deste e de outros Pontos de Cultura reinstalou os conflitos no campo cultural de São Luiz do Paraitinga. Crises nas relações entre os agentes, falta de apoio institucional, dificuldade de encontrar proponente voltam à gramática da política cultural da cidade. Neste modelo de agenciamentos culturais individuais, as relações pessoais e familiares são fundamentais na modulação de alianças e apoios aos projetos propostos. No caso de Pedro, ocorre algo semelhante: estava com o projeto em fase final de redação, mas não encontrava entidade proponente que operacionalizasse sua submissão. Na experiência de nosso informante, sua esposa teve dupla importância:

1) realizou a redação do projeto e a organização burocrática da documentação a encaminhar a Brasília; e

2) para ser o proponente do Ponto de Cultura precisava ter dois anos de atividade em organização não-governamental ou associação, com pessoa jurídica. Pedro havia ficado sem proponente, pensava em encontrar um de fora de São Luiz, mas a Casa da Amizade, cuja presidente é tia de sua esposa, aceitou.

A entidade entendera a parceria como vantajosa, pois todos os equipamentos adquiridos ficariam sob guarda e uso da instituição.

Após o desafio da parceria com uma organização, a necessidade tornou-se a atualização do projeto e uma nova racionalização das atividades previstas, isto é, o planejamento político e pedagógico das ações culturais fazia-se fundamental, como destaca seu coordenador:

O projeto mantém a mesma essência que tinha antes, como eu pensei antes. Nós aqui em São Luiz estamos vivendo, e eu digo isso particularmente, a gente vive muito o passado. Não se tem mais grupos folclóricos como se tinha há 20 ou 30 anos atrás. São Luiz chegou a ter 22 congadas, somando com a zona rural, eram 22, hoje a cidade tem uma congada. Agora que nós montamos outra, tem duas. O projeto está voltado para isso mesmo, tentar resgatar um pouco desta história, não é nem para preservar, é resgatar, por isso que eu montei uma congada, por isso que eu trabalho com isso. Na nossa congada a minha filha que tem onze anos canta, tenho uma filha de quatro anos que também canta na congada, a gente está trazendo as crianças, tem professores que participam da congada, tem intelectual, pessoas da imprensa, jornalista, são pessoas de telejornais que estão aqui com a gente, professores aposentados, enfim todas as classes sociais estão na congada. (Pedro, 45 anos).

O projeto revelava a necessidade de associar as atividades do Ponto de Cultura às escolas, professores e alunos do município, reposicionando a formação cultural como conteúdo expressivo da atividade. Tal objetivo exigiu a seleção de uma série de manifestações da cultura local ou regional 
cujo sentido fosse compartilhado nestes horizontes possíveis de ação, o que exigiu uma "reconstrução de manifestações expressivas" (Martins, 2009). Por exemplo, ao constatar a redução significativa de grupos de congada no município, projetou uma ação cultural com a maioria de seus participantes residentes fora da cidade, sendo intelectuais, jornalistas e pessoas da imprensa, entre outros, o que conforma uma técnica de vida observável nas políticas culturais contemporâneas: a reconstrução de manifestações expressivas, com foco na identidade regional, mas sob uma atualização comercial ou midiática.

Essa atualização chegou a provocar tensionamentos e ser contestada entre os agentes culturais de São Luiz:

Montamos essa congada, algumas pessoas até estão falando que nós estamos fugindo das origens, nós somos um grupo de artistas, nós estamos representando o que é, com composições nossas e no intuito de fortalecer o que existe, no intuito de que volte às origens, para que as pessoas se animem e voltem a fazer aquilo que se fazia. O Ponto de Cultura entra nisso. (Pedro, 45 anos).

A referência feita por Pedro a "uma volta às origens" torna-se interessante na produção pedagógica de suas ações, uma vez que explicita uma ambivalência própria a outros grupos de congada e moçambique já estudados (Lopes, 1995). Seu intuito de voltar à origem, por um lado, explicita-nos o objetivo de patrimonializar uma prática cultural em declínio naquele contexto e, por outro, indica-nos o uso de estratégia tradicional de legitimidade destes grupos, qual seja, a composição familiar. Os grupos familiares constituem unidades endógenas ao grupo folclórico, sendo que compõem "grupos dentro do grupo" (Lopes, 1995), onde, em circunstâncias específicas, famílias mais numerosas são beneficiadas em disputas materiais ou simbólicas no interior do agrupamento.

O projeto, além da reconstrução de um grupo de congada, possuiu outras frentes de trabalho que pretendem resgatar a identidade cultural caipira presente na cidade, através de dispositivos pedagógicos que ora se situam no interior das práticas formativas, ora se projetam nas relações entre os atores sociais e a cidade, em sentido mais amplo. Uma destas projeções foi a dimensão rítmica da cultura caipira, definida entre os ritmos do Congo e as marchinhas de carnaval. Foram previstas oficinas de construção de instrumentos musicais, mediante contratação de mestre especialista nesses fazeres, e o ensino da arte às pessoas, especificamente na confecção de instrumentos de madeira, corda e couro.

Outro segmento tratado no projeto foram os bonecões, estes considerados ícones das festas locais de carnaval. Vários bonecos da cidade se perderam com a enchente, então pretendiam ajudar a refazer os bonecões, a criar novos, inclusive fornecer uma melhor estrutura para a presença deles nas festas religiosas e nos blocos de carnaval das comunidades. Associada a esta intenção, planejaram oficinas de corte e costura para as mulheres, especialmente aquelas que trabalham como artesãs no Mercado Municipal e que perderam todos os seus retalhos 
com a enchente. Visavam, pois, a confecção de roupas para os bonecos e para os grupos folclóricos da cidade, além de utilizarem as máquinas de costura para refazer os estoques artesanais perdidos.

Outra perspectiva do planejamento do Pontão foi a produção de uma orquestra de cordas. A intenção de Pedro, quando da projeção desta ação institucionalizada, era a seguinte:

Nós vamos ter um instrutor de viola caipira, o mesmo vai dar aulas de violão, também vamos ter um instrutor de violino, que vai dar aula de rabeca e rabecão. Vamos montar uma orquestra com 40 pessoas inicialmente, utilizando as oficinas de ritmo também. A ideia inicial era que esses alunos tivessem uma bolsa, cada aluno tivesse seu ganho de 150 ou 100 reais todo mês para estudar música, mas como o valor do projeto não atingiu para a gente fazer isso, não deu. Mas a gente pretende ainda construir a orquestra e encaminhar essa proposta para outra empresa, como a Petrobrás, para tentar conseguir outro financiamento. (Pedro, 45 anos).

Além disso, a última ênfase do projeto foi a valorização da cozinha caipira. Quando criou a primeira versão do projeto no período em que trabalhou no museu, viu, na época, a possibilidade de montar uma cozinha tradicional, de pau a pique, com fogão a lenha - nos termos de Pedro, "bem cabocla mesmo!" Os interesses desta etapa do planejamento foram, além da cozinha propriamente dita, a criação de um evento de divulgação das ações do próprio Ponto de Cultura, como expressa o fragmento que segue:

E criei esse projeto pensando mais ou menos isso, uma vez a cada bimestre ou trimestre você apresenta as atividades do ponto para a comunidade, chama os grupos folclóricos envolvidos, aos poucos, e preparava um banquete para todos, com o compromisso de apresentarem o que fazem a todos. Poderiam ser vendidos alguns ingressos, e o dinheiro recolhido seria dos grupos. Teriam oficinas também, a cada período convidávamos um cozinheiro acostumado a preparar comida para grande quantidade de pessoas e ele cozinharia nesse encontro, o que já é comum aqui. A comida seria catalogada e estaria à disposição da rede de pontos do Brasil. (Pedro, 45 anos).

A experiência pedagógica do Ponto de Cultura revelou um duplo interesse formativo. Primeiro, a formação de estudantes das escolas públicas municipais na recuperação de práticas culturais tradicionais e valorização dos saberes, fazeres e valores próprios de uma cultura rural ou caipira, reconstruindo-os seletiva e expressivamente. As atividades planejadas orientaram-se por um desejo pedagógico de mobilizar experiências de educação patrimonial, onde a cultura local (em suas múltiplas manifestações identitárias: dança, culinária, música, artesanato, etc.) se tornava conteúdo e prática de uma aprendizagem ocorrida na escola, mas projetada para além de seus muros.

Segundo, os interesses formativos situados no planejamento político e pedagógico do Ponto de Cultura ora analisado, além dos fazeres escolares, estiveram centrados na valorização dos modos de viver em São Luiz do Paraitinga, cidade recentemente abalada por incidente natural. Ao 
tratar das questões culturais próprias do lugar, o objetivo foi recuperar a autoestima dos habitantes, restabelecendo vínculos e pertencimentos dos atores à cidade. Observamos, mediante ações culturais de educação patrimonial, a circulação de pedagogias voltadas à reconstrução de narrativas de sentido social (Silva, 2012) e reconhecimento das produções identitárias locais.

\section{Considerações finais}

O modelo de agenciamento cultural explicitado neste texto configura uma técnica de vida (Simmel, 1979), ao constituir-se em determinante que estabelece limites específicos que condicionam a ação dos indivíduos nas políticas culturais contemporâneas. Desde a análise que realizamos, identificamos pesos e influências distintas entre fatores econômicos, políticos e sociais que tangenciam os projetos culturais, algumas vezes mais próximos de políticas nacionais de cultura, como o imperativo da lógica de editais na seleção de programas ou as leis de incentivo em suas faces específicas, outras vezes mais aproximados das práticas sociais dos atores participantes deste campo, como os agenciamentos pessoais ou os interesses locais em jogo. Porém, duas características são recorrentes nesta interpretação: o interesse na institucionalização do projeto cultural e a conformação de um novo arranjo das "forças plurais" (Simmel, 1946) em dinâmicas competitivas ou concorrenciais em escala local.

Assim, de certo modo, este artigo explicitou um modelo de agenciamento individual, identificado nas disputas por Pontos de Cultura em São Luiz do Paraitinga, SP. A institucionalização do projeto se deu através de dispositivos de racionalização das ações (planos, estratégias, objetivos político-organizacionais). Contudo, esses projetos exigem agenciamentos em um campo de disputas individuais e forças postas no âmbito local, os quais são realizados desde relações pessoais, familiares, profissionais e políticas de seus proponentes. Estas disputas e concorrências reorganizam as "forças plurais" na cidade, personalizando a identificação entre o projeto e seu idealizador.

Desta maneira, forma campos concorrenciais endógenos ao município, entre projetos e agentes portadores de experiências prévias (Schutz, 1974) voltados à efetuação de iniciativas que reformulem ou ampliem ações em curso. Os projetos são desenvolvidos segundo as experiências e "conhecimentos que seus atores dispõem à mão" (Schutz, 1974) no momento, o que correlaciona projeto cultural e suas experiências sociais com maior autonomia dos atores à formulação de projeções, como se explicita na situação de Pedro.

No entanto, uma observação sociológica mais ampla pode ser deduzida do relato empírico da cidade valeparaibana, o qual acompanha uma característica própria das políticas socioculturais de nosso tempo. Atualmente, as políticas socioculturais são construídas na condição de ambivalência entre a emergência de campos concorrenciais entre projetos 
e atores culturais em busca de diversos recursos e a reconfiguração de modelos valorativos voltados para a reconstrução dos sentidos sociais. Assim, experiências políticas como a do Programa Cultura Viva contribuem na democratização destas ações, pois visam disputas menos desiguais por recursos políticos, sociais e econômicos. Portanto, estas políticas formativas de natureza sociocultural situam-se na dinamização de novos ordenamentos sociais, econômicos e políticos, mas, concomitantemente, associados a ações centradas na formação dos atores sociais.

Por um registro educativo, observamos na situação investigada, mediante ações culturais de educação patrimonial, a circulação de pedagogias voltadas à reconstrução de narrativas de sentido social (Silva, 2012) e o reconhecimento político das produções identitárias em escalas locais.

\section{Referências bibliográficas}

ANICO, M. A pós-modernização da cultura: património e museus na contemporaneidade. Horizontes Antropológicos, Porto Alegre, v. 11, n. 23, p. 71-86, jan./jun. 2005.

ARANTES, O. B. F. Uma estratégia fatal: a cultura nas novas gestões urbanas. In: ARANTES, O. B. F.; VAINER, C.; MARICATO, E. (Org.). A cidade do pensamento único: desmanchando consensos. 5. ed. Petrópolis: Vozes, 2009. p. 11-73.

BARBALHO, A. Políticas culturais no Brasil: identidade e diversidade sem diferença. In: RUBIM, A. A. C.; BARBALHO, A. (Org.). Políticas culturais no Brasil. Salvador: Edufba, 2007. p. 37-60.

BARBOSA, F. Ministério da Cultura no governo Luiz Inácio Lula da Silva: um primeiro balanço. In: CALABRE, L. (Org.). Políticas culturais: um campo de estudo. Rio de Janeiro: Casa Rui Barbosa, 2008. p. 59-86.

BORJA, J.; CASTELLS, M. Local y global: la gestión de las ciudades en la era de la información. Buenos Aires: Taurus, 1997.

BRASIL. Ministério da Cultura (MinC). Plano Nacional de Cultura: diretrizes gerais. 2. ed. Brasília: Minc, Comissão Permanente de Educação e Cultura da Câmara dos Deputados, 2008. Disponível em: $<$ www.cultura.gov.br/pnc $>$.

BRASIL. Ministério da Cultura (MinC). Programa Cultura Viva: objetivos e público [on line]. 28 fev. 2013. Disponível em: <http://www.cultura. gov.br/culturaviva/cultura-viva/objetivos-e-publico/> . 
BRASIL. Ministério da Cultura (MinC). São Luiz do Paraitinga: Ministério da Cultura promove série de ações em apoio à cidade histórica do interior paulista. 2 fev. 2010. Disponível em: < http://www.cultura.gov. br/site/2010/02/02/sao-luiz-do-paraitinga/>.

CALABRE, L. Políticas culturais no Brasil: dos anos 1930 ao século XXI. Rio de Janeiro: Ed. FGV, 2009.

CANCLINI, N. G. A globalização imaginada. São Paulo: Iluminuras, 2003.

CAVALIERE, A. M. V. Educação integral: uma nova identidade para a escola brasileira. Educação \& Sociedade, Campinas, v. 23, n. 81, p. 247-270, dez. 2002.

CORRÊA, A. F. Desafios à política cultural e a nova museologia: patrimônio, memória e desenvolvimento. In: REUNIÃO DE ANTROPOLOGIA DO MERCOSUL (RAM), 7., 2007, Porto Alegre. Anais... Porto Alegre: RAM, 2007. [CD-ROM].

CURY, C. E. Políticas culturais no Brasil: subsídios para a construção da brasilidade. 2002. Tese (Doutorado em Educação) - Universidade Estadual de Campinas (Unicamp), 2002.

DEWEY, J. Em busca do público. In: FRANCO, A.; POGREBINSCHI, T. Democracia cooperativa: escritos políticos escolhidos de John Dewey. Porto Alegre: EdiPUC-RS, 2008.

DEWEY, J. Liberalismo, liberdade e cultura. São Paulo: Ed. Nacional/ USP, 1970.

DUBET, F. Conflictos de normas y ocaso de la institución. Estudios Sociológicos, México, DF, v. 22, n. 1, p. 3-24, enero/abr. 2004.

DUBET, F. El declive y las mutaciones de la institución. Revista de Antropología Social, Madrid, v. 16, p. 39-66, 2007.

FARIAS, E. Ócio e negócio: festas populares e entretenimento-turismo no Brasil. Tese de Doutorado em Ciências Sociais. Universidade Estadual de Campinas, 2001.

JACQUES, P. B. Espetacularização urbana contemporânea. Cadernos PPG-AU, FAUFBA, Salvador, v. 2, n. 2 [número especial], p. 23-29, 2004.

JEUDY, H. P. Reparar: uma nova ideologia cultural e política? In: JEUDY, H. P.; JACQUES, P. B. (Org.). Corpos e cenários urbanos: territórios urbanos e políticas culturais. Salvador: Edufba, 2006. p. 13-24. 
KARA-JOSÉ, B. Políticas culturais e negócios urbanos: a instrumentalização da cultura na revitalização do Centro de São Paulo 1975-2000. São Paulo: Annablume, Fapesp, 2007.

LOPES, J. R. A cultura como crença: estratégias modernas de reprodução da vida popular. Taubaté: Cabral, Robe Editorial, 1995.

LOPES, J. R. Industrialização e mudanças culturais no Vale do Paraíba, SP. In: CHAMON, E. M. Q. O.; SOUSA, C. M. (Org.) Estudos interdisciplinares em Ciências Sociais. Taubaté: Cabral, 2006.

LOPES, J. R; SILVA, A. L.; SILVA, R. M. D. O Divino, o patrimônio e a cidade: uma análise de modulações culturais provocadas por eventos críticos. Ciências Sociais Unisinos, São Leopoldo, v. 47, n. 3, p. 208217, set./dez. 2011.

MARTINELL, A. Cultura e cidade: uma aliança para o desenvolvimento - a experiência da Espanha. In: Políticas culturais para o desenvolvimento: uma base de dados para a cultura. Brasília: Unesco Brasil, 2003.

MARTINS, P. Cabo-verdianos em Lisboa: manifestações expressivas e reconstrução identitária. Horizontes Antropológicos, Porto Alegre, v. 15, n. 31, p. 241-269, jan./jun. 2009.

ROTMAN, M. Património e producciones artesanales de comunidades Mapuche de Neunquén: Estado, mercado y tradición como "fuentes" de legitimidad. In: REUNIÃO DE ANTROPOLOGIA DO MERCOSUL (RAM), 7., 2007, Porto Alegre. Anais... Porto Alegre: RAM, 2007. [CD-ROM].

RUBIM, A. A. C. As políticas culturais e o governo Lula. São Paulo: Perseu Abramo, 2011.

SANT'ANNA, M. A cidade-atração: patrimônio e valorização de áreas centrais no Brasil dos anos 90. Cadernos PPG-AU, FAUFBA, Salvador, v. 2, n. 2 [número especial], p. 43-58, 2004.

SANTOS, J. R. C. C. A Festa do Divino de São Luiz do Paraitinga: o desafio da cultura popular na contemporaneidade. Mestrado em História Social. Universidade de São Paulo, 2008.

SCHUTZ, A. El problema de la realidad social. Buenos Aires: Amorrortu, 1974.

SILVA, F. B.; ARAÚJO, H. E. (Org.) Cultura viva: avaliação do programa Arte, Educação e Cidadania. Brasília: Ipea, 2010.

SILVA, A. L. A conveniência da cultura popular: um estudo sobre a pluralidade de domínios, danças devocionais e a ação dos mestres no Vale do Paraíba. 2011. Tese (Doutorado em Ciências Sociais) - Pontifícia Universidade Católica de São Paulo, 2011. 
SILVA, R. M. D. Políticas culturais em cidades turísticas brasileiras: um estudo sobre as técnicas de vida contemporâneas. 2012. Tese (Doutorado em Ciências Sociais) - Universidade do Vale do Rio dos Sinos, São Leopoldo, RS, 2012.

SILVEIRA, C. B. Projetos urbanos culturais na cidade do Rio de Janeiro. In: JEUDY, H. P.; JACQUES, P. B. (Org.). Corpos e cenários urbanos: territórios urbanos e políticas culturais. Salvador: Edufba, 2006. p. 93104.

SIMMEL, G. Cultura femenina y otros ensayos. 5. ed. Buenos Aires: Espasa-Calpe, 1946.

SIMMEL, G. A metrópole e a vida mental. In: VELHO, O. (Org.). O fenômeno urbano. 4. ed. Rio de Janeiro: Zahar, 1979.

UNESCO. Marco estratégico para a Unesco no Brasil. Brasília, 2006.

VAZ, L. F. A "culturalização" do planejamento e da cidade: novos modelos. Cadernos PPG-AU, FAUFBA, Salvador, v. 2, n. 2 [número especial], p. 31-42, 2004.

VAZ, Lilian Fessler; JACQUES, Paola Berenstein. Territórios culturais na cidade do Rio de Janeiro. In: JEUDY, Henri-Pierre; JACQUES, Paola Berenstein. Corpos e cenários urbanos. Salvador, Edufba, 2006. p. 75-91. Disponível em: <www.laboratoriourbano.ufba.br/download. php?idArquivo $=12>$.

XAVIER, L. P. "Aqui... a gente não vende cerâmica, a gente vende é cultura" - patrimônio material e estratégias regionais de desenvolvimento. In: REUNIÃO DE ANTROPOLOGIA DO MERCOSUL (RAM), 7., 2007, Porto Alegre. Anais... Porto Alegre: RAM, 2007. [CDROM].

YÚDICE, G. A conveniência da cultura: usos da cultura na era global. Belo Horizonte: Ed. UFMG, 2004.

Rodrigo Manoel Dias da Silva, doutor em Ciências Sociais pela Universidade do Vale do Rio dos Sinos (Unisinos), é professor de Sociologia e Política na Universidade Federal da Fronteira Sul (UFFS), Campus Erechim.

rodrigoddsilva@hotmail.com

Recebido em 11 de maio de 2011.

Aprovado em 7 de novembro de 2012. 